\title{
Multidisciplinary approach to lacrimal system diseases
}

\author{
Approccio multidisciplinare alle patologie del sistema lacrimale \\ Matteo Trimarchi1 ${ }^{1,2}$, Alessandro Vinciguerra ${ }^{1,2}$, Antonio Giordano Resti ${ }^{3}$, Leone Giordano ${ }^{1}$, Mario Bussi ${ }^{1,2}$ \\ ${ }^{1}$ Otorhinolaryngology Unit, Head and Neck Department, IRCCS San Raffaele Scientific Institute, Milan, Italy; ${ }^{2}$ School of Medicine, \\ Vita-Salute San Raffaele University, Milan, Italy; ${ }^{3}$ Ophthalmologic Unit, Head and Neck Department, IRCCS San Raffaele Scientific \\ Institute, Milan, Italy
}

\begin{abstract}
SUMMARY
Pathologies of the lacrimal drainage system range from benign to malignant lesions. However, independently of the etiological origin, the most common presenting symptom is represented by epiphora due to the dysfunction of the lacrimal system. Different diagnostic tools are now available, but for the most the first diagnostic approach is characterized by an ophthalmological visit, associated with nasal endoscopy, usually performed by an otolaryngologist. Frequently the diagnostic work-up is completed with a radiological exam (e.g. maxilla-facial CT or dacryocystography), whose role is still to be determined. Once a diagnosis has been made, different treatments are available in relation to the type of the disease, and commonly need close cooperation between an ENT and ophthalmic surgeon given the close anatomical structures involved. Taking into account all these aspects, the aim of this review is to highlight how a multidisciplinary approach to lacrimal pathologies is mandatory from diagnosis to treatment in order to offer the best clinical approach.
\end{abstract}

KEY WORDS: multidisciplinary approach, dacryocystorhinostomy, lacrimal pathology, nasolacrimal duct, lacrimal obstruction

\section{RIASSUNTO}

Le patologie della via lacrimale variano da malattia di natura benigna a maligna. Indipendentemente dall'origine etiologica, il sintomo di presentazione clinica più frequente è rappresentato dall'epifora, causata dalla disfunzione della via lacrimale. Oggigiorno sono disponibili diversi strumenti diagnostici per questo tipo di patologia ma, per la maggior parte della comunità scientifica, il primo step diagnostico è rappresentato dalla visita oftalmologica, associato a un'endoscopia nasale eseguita solitamente da un otorinolaringoiatra. Frequentemente, questo work-up diagnostico è completato da un esame radiologico (es: Tomografia Computerizzata o Dacriocistografia), il cui ruolo è ancora da determinare. Una volta eseguita una corretta diagnosi, differenti opzioni terapeutiche sono attualmente disponibili in relazione alla tipologia eziologica ed è necessaria, frequentemente, una stretta collaborazione tra otorinolaringoiatra e oculista, dati gli stretti rapporti anatomici delle strutture coinvolte.

Tenendo in considerazione gli aspetti sopracitati, lo scopo della presente review è di evidenziare come l'approccio multidisciplinare alla patologia delle vie lacrimali sia mandatorio dalla diagnosi alla terapia, in modo da offrire al paziente un approccio clinico ottimale.

PAROLE CHIAVE: approccio multidisciplinare, dacriocistorinostomia, patologia della via lacrimale, dotto naso-lacrimale, ostruzione lacrimale

\section{Introduction}

The lacrimal drainage system (LDS) is a complex apparatus that is responsible for flow of tears from the eye (medial cantus) to the nasal cavity (inferior meatus). Any pathology of this system usually appears as watery eye, also known as epiphora, which is a common clinical sign that can be caused by different
Received: October 25, 2020

Accepted: January 21, 2021

Correspondence

Matteo Trimarchi

Otolaryngology Department, San Raffaele Hospital, via Olgettina 68, 20100 Milan, Italy

Tel. +3902 26432172

E-mail: trimarchi.matteo@hsr.it

Funding

None.

Conflict of interest

The Authors declare no conflict of interest.

How to cite this article: Trimarchi M, Vinciguerra A, Resti AG, et al. Multidisciplinary approach to lacrimal system diseases. Acta Otorhinolaryngol Ital 2021;41(SUPPL.1):S102-S107. https://doi.org/10.14639/0392-100X-suppl.1-41-2021-10

(C) Società Italiana di Otorinolaringoiatria e Chirurgia Cervico-Facciale

\section{(c) (1) $(2)$}

This is an open access article distributed in accordance with the CC-BY-NC-ND (Creative Commons Attribution-NonCommercial-NoDerivatives 4.0 International) license. The article can be used by giving appropriate credit and mentioning the license, but only for non-commercial purposes and only in the original version. For further information: https:// creativecommons.org/licenses/by-nc-nd/4.0/deed.en 
factors that are mainly classified as reduced outflow (e.g. lacrimal obstruction, eyelid malposition), hypersecretion of tears and reflex tearing ${ }^{1}$. Among all these, lacrimal obstruction is the most common cause and can be distinguished in congenital, if it appears before the first year of life, and acquired forms ${ }^{2,3}$. Additionally, if considered the site of the obstruction, it can also be divided in proximal (punctum, superior, inferior and common canaliculus) and distal (or post-canalicular) lacrimal obstruction, which is the most common ${ }^{2}$. The latter form is most commonly encountered in middle-aged female patients in whom different local and systemic pathologies may cause lacrimal obstruction 1,4-12. Regardless of its etiology, epiphora has substantial impact on the quality of life, thus making its correct approach fundamental ${ }^{13,14}$. In past years, lacrimal pathologies were mainly managed by an ophthalmologist due to the clinical presentation and the treatments that were available. Nowadays, with the advent of rigid endoscopes, the approach of these types of pathologies has radically changed, leading to cooperation with an otolaryngologist (ENT). Moreover, thanks to this technological implementation, not only has it permitted executing standard dacryocystorhinostomy through an endonasal endoscopic approach (END-DCR), but it has also gained a major role pre-operatively: in fact, endoscopic analyses of the nasal fossa permits direct and optimal identification of surgical landmarks and anatomi- cal variations that can affect the surgery (e.g. nasal septum deviation, paradoxical middle turbinate). Additionally, endoscopic instrumentation can be used post-operatively, thanks to the importance of direct visualization of the healing process. Surprisingly, it has been reported that nasal examination is not usually performed by most ophthalmologists, with potential consequences on treatment outcomes ${ }^{15}$.

In the past, several authors have tried to identify the best clinical practice for lacrimal diseases, but no one has taken into account the role of multidisciplinary consultation between an ophthalmologist and otorhinolaryngologist in the management of lacrimal pathologies. The aim of this review is to analyze the role of a multidisciplinary approach to lacrimal pathologies, from the diagnosis to treatment.

\section{Diagnosis}

The pathologies that may affect the lacrimal pathway are numerous and differential diagnosis between them can be challenging ${ }^{16}$. The finer aspects of a precise assessment of the lacrimal pathology is beyond the scope of this paper. However, most of the literature agrees that in-office ophthalmologic examination is the first diagnostic step that should be taken in case of suspicion of lacrimal pathologies (Fig. 1) ${ }^{17}$. In fact, clinical examination provides an assess-

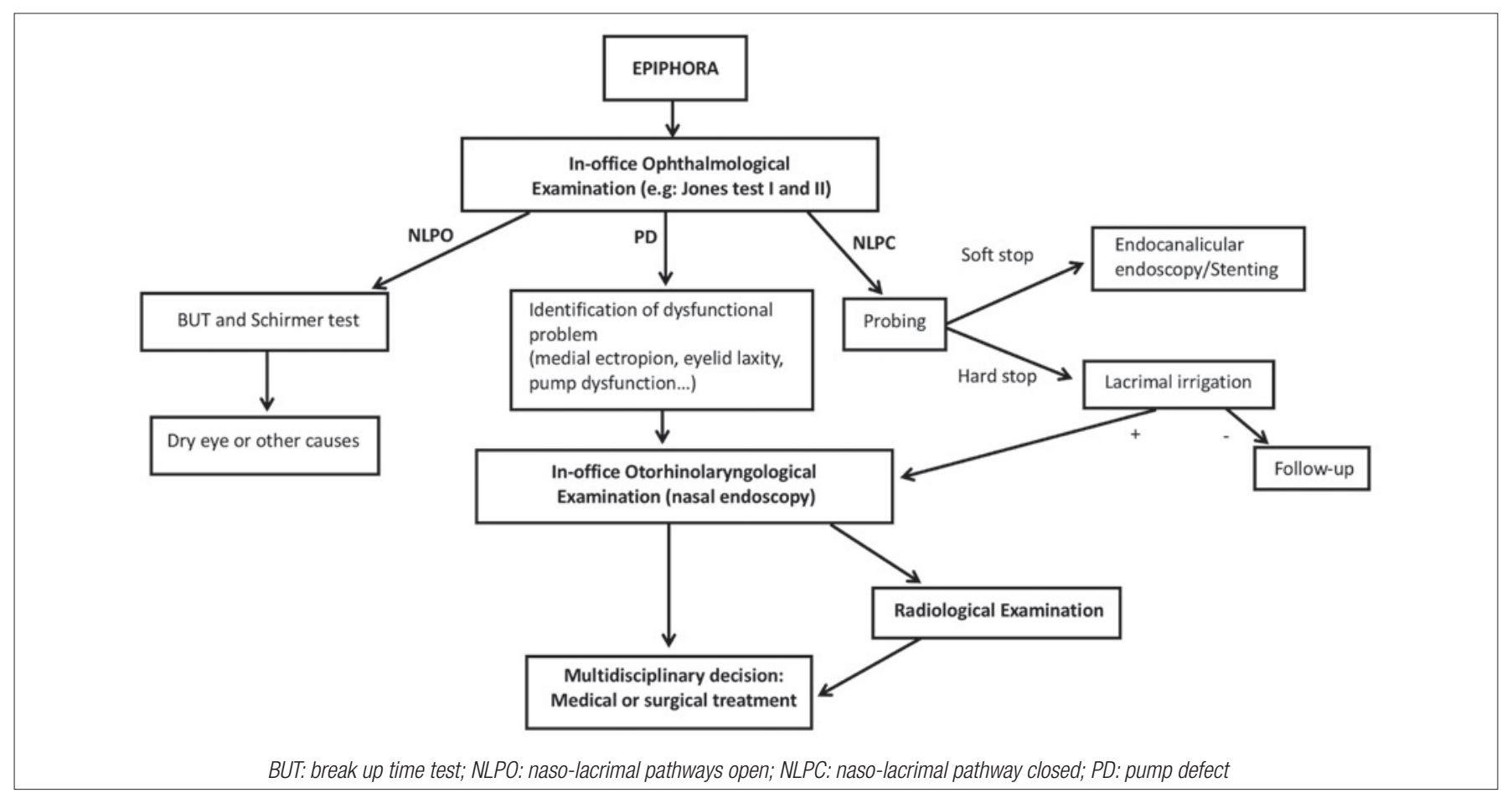

Figure 1. Multidisciplinary diagnostic flow-chart for epiphora. 
ment of lacrimal structures, eyelids, punctal position, meibomian gland, lacrimal gland and possible pathology of the ocular bulb, providing an initial differential diagnosis of the primary lacrimal pathway pathologies to secondary ones and its potential functional/obstructive nature ${ }^{1}$. Such an initial diagnostic step is a non-invasive, easy and low-cost way to establish an initial diagnosis, and if the result of this examination confirms a pathology of the eyelid, lacrimal gland, ocular bulb or meibomian gland, an otolaryngologist is not always required ${ }^{16}$. On the contrary, clinical examination of the nasal cavities by an otolaryngologist remains of major interest in case of both functional and obstructive lacrimal pathway pathologies ${ }^{15}$. In fact, even if in some lacrimal pathologies, like functional diseases, the available treatments are primarily performed by an ophthalmologist, the role of an otolaryngologist remain fundamental since he can provide an endoscopic assessment of the nasal fossa, excluding any form of influencing factors ${ }^{15}$. Similarly, in case of lacrimal obstructive pathologies, endoscopic assessment of the nose is important for diagnostic purposes (e.g. presence of neoplastic mass), direct evaluation of the endonasal space that can influence the decision of the treatment to be performed, and for identification of the potential surgical influencing factors such as the nasal septum deviation, nasal mucosa pathologies, paradoxal middle turbinate, and abnormalities of the nasal fossa ${ }^{8}$.

As a result, to establish the best diagnosis for each patient affected with a pathology of the lacrimal drainage system, accurate and specific work-up is fundamental and needs to be done through multidisciplinary consultation between an ophthalmologist and otorhinolaryngologist.

In addition to this, different radiological studies are now available with the aim of precise identification of the lacrimal disease etiology: in particular, this diagnostic step is fundamental in case of neoplastic disease, since the clinical presentation of the tumor can be non-specific, such as medial cantus tender mass, bloody tears and epiphora, painless and with no endoscopic endonasal signs ${ }^{11}$. Nevertheless, its application in non-oncologic lacrimal pathologies is controversial ${ }^{17}$. A recent survey has demonstrated a relative lack of interest for lacrimal imaging among ophthalmic plastic surgeons ${ }^{18}$. However, there are times in which a specific diagnosis remains unclear and imaging of the lacrimal system may be used to help evaluate its function and anatomy. Specifically, Lefebvre et al. suggested that radiologic tools must be used in case of neoplastic suspicion and should be applied in case of re-operation or when there is suspicion of complicated anatomy ${ }^{17}$. The adjunctive information that can be obtained through radiological exams are important for both ophthalmic and ENT surgeons since they can provide the exact position of the obstruction and presence of anatomical malformation that can be missed with clinical/endoscopic exam ${ }^{16}$.

At present, different imaging techniques are available (e.g. maxillo-facial CT, dacryocystography, MRI, dacryoscintigraphy, single-photon emission computed tomography); however, no unanimous consensus on the gold standard radiologic tool has been achieved ${ }^{17}$.

\section{Treatment}

Given the large range of lacrimal pathologies described, analysis of their treatment needs to be divided into proximal and distal lacrimal pathologies, related to the site of the disease. A complete assessment of the possible treatments available for lacrimal pathologies is beyond the scope of this manuscript, although generally speaking collaboration between an ENT surgeon and ophthalmologist is mandatory in distal lacrimal obstructions, whereas in proximal pathologies it can be recommended in relation to the type of the disease. Conversely, in case of a pump defect or functional disease, multidisciplinary treatment is not generally required since these are primary ophthalmologic pathologies.

\section{Proximal lacrimal obstructions}

Lacrimal pathologies proximal to the valve of Rosenmuller are mainly divided into punctum (e.g. punctual stenosis, punctual membrane, cicatrizing disease) and canaliculus disease (e.g. stenosis, scarring and foreign bodies) ${ }^{1}$. If the former can be generally treated with punctoplasty, i.e. a surgical procedure with the aim of widening the tight punctum, canaliculus disease can be approached conservatively or surgically. In particular, a probing stenting of the proximal lacrimal pathway can be done and, if not successful, conjunctivodacryocystorhinostomy can be perfomed. The latter is a surgical procedure that creates a neo-passage from the conjunctiva to the middle meatus of the nose ${ }^{19}$. All the treatments described for proximal obstruction of the lacrimal pathway are generally performed by an ophthalmic plastic surgeon and the collaboration with an ENT is not always mandatory. However, conjunctivodacryocystorhinostomy is an approach in which the otolaryngologist can be helpful, since endoscopic assessment of the nasal cavity allows easy visualization of the correct position of the lacrimal tube and implementation of nasal co-interventions during the approach ${ }^{20}$.

Nevertheless, these rules concern benign lesions since malignant ones require close collaboration with the ENT surgeon: in fact, even if a primary malignancy of the proximal lacrimal tract is rare, stenosis of the lacrimal pathway secondary to extrinsic compression due to sino-nasal, or- 


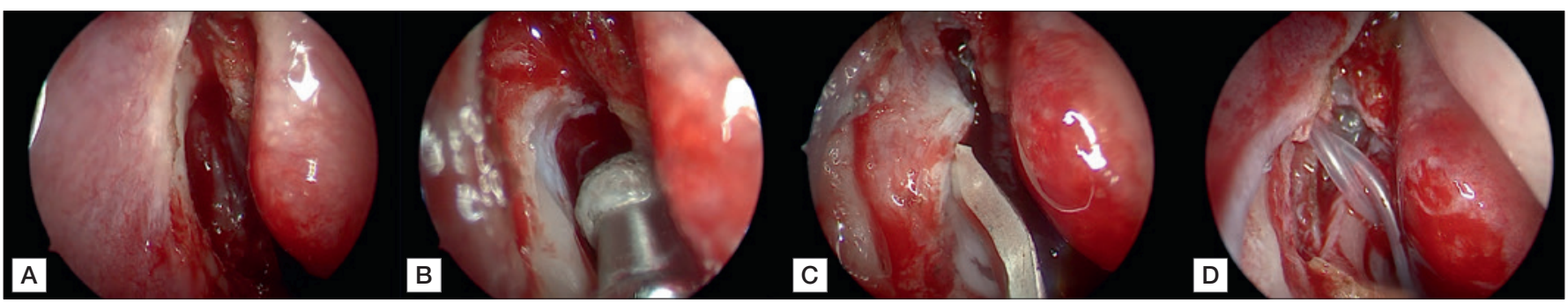

Figure 2. Endoscopic dacryocystorhinostomy surgical procedure. (A) Using $30^{\circ}$ endoscope, the maxillary line is identified and a mucosal flap ("L-shaped") is raised posteriorly to expose the lacrimal bone; (B) the lacrimal bone is than removed using powered instrument; (C) while a Bowman's probe was used by an ophthalmologist to tent the medial sac, the ENT surgeon used its as a guide to make a vertical incision of the lacrimal sac; (D) the initial mucosal flap is reflected back and the ophthalmologist positioned a bicanalicular stent that is retrieved endonasally and looped.

bital and cutaneous malignancy can occur and needs to be treated in a multidisciplinary manner in order to eradicate the tumor and re-establish functional eye to nose tear flow.

\section{Distal lacrimal obstructions}

Distal acquired lacrimal obstructions present different treatments related to the etiology and age of the patient. In general, the most common location of the stenosis of this form is the nasolacrimal duct (NLD) ${ }^{9}$.

If the congenital form is taken into account, lacrimal duct closure is usually caused by a mucosal membrane at the level of Hasner's valve or by a bony constriction of the NLD ${ }^{21,22}$. Congenital NLD obstruction is commonly managed conservatively: in particular, most patients experience spontaneous resolution of the pathology by the end of the first year, thanks to a bony development that allows an enlargement of the lacrimal duct ${ }^{23}$. Some clinicians usually prescribe a non-invasive procedure, Crigler's lacrimal sac compression, with which a simple inward lacrimal compression of the lacrimal sac enhances hydrostatic pressure within the system in order to overcome the common membranous obstruction ${ }^{24}$. As an alternative, a stenting-probing of the lacrimal system can be performed ${ }^{25}$. All these different approaches, commonly performed by an ophthalmic plastic surgeon, provide a success rate of up to $90 \%$. In the event of challenging cases, endoscopic endonasal dacryocystorhinostomy (END-DCR) is an established procedure to address unmanageable congenital obstructions, making a multidisciplinary approach with an ENT a possibility in case of this refractive form ${ }^{26}$.

Considering the adult form of distal lacrimal obstruction (DALO), the most common pathologies can be distinguished as oncologic and non-oncologic (primary and secondary) forms. Primary acquired and secondary, nononcologic, diseases have several treatments available, both surgical and non-surgical, that can be performed by different clinicians. Among all, a recent review has pointed out that external dacryocystorhinostomy (EXT-DCR) and
END-DCR present higher functional success rates compared to other techniques, and should be considered as treatments of choice ${ }^{27}$. In these cases, the collaboration between ophthalmic plastic and ENT surgeons is necessary because, if a END-DCR is performed, management of the proximal lacrimal pathway is required and needs the presence of the ophthalmologist (Fig. 2); conversely, if an EXT-DCR is performed, endoscopic direct visualization of the surgical landmark and potential anatomic variation can be helpful in order to decrease potential influencing factors of the surgical outcome ${ }^{15}$.

If a secondary re-stenosis of the neo-rhinostomy occurs, END-DCR seem to be the treatment of choice since it provides direct visualization of intranasal abnormalities which cause surgical failure, with no superiority demonstrated over EXT-DCR ${ }^{28}$. In addition to this, a new endoscopic approach has been proposed, based on endonasal balloon dilatation of the stenotic neorhinostomy, with encouraging data ${ }^{29,30}$ (Fig. 3). In general, it seems that both primary and secondary approaches to non-oncologic DALO would benefit from a multidisciplinary approach ${ }^{28}$.

Malignancies of the distal lacrimal pathway have a wide range of histologies, with an epithelial origin the most common form. In general, treatment is based on complete and wide surgical resection, which commonly requires excision of adjacent structures. As a result, considering the necessary reconstruction of the lacrimal pathway and the potential combined approach to the orbital area, a multidisciplinary approach is indispensable ${ }^{11}$.

\section{Post-surgical management and follow-up}

Following proper treatment, several post-surgical medical therapies are available, and, seem particularly useful in case of non-oncologic DALO. However, with the available data, the actual influence of adjunctive medical therapies is difficult to demonstrate ${ }^{31}$, and endoscopic visualization of the healing process associated with nasal medication 


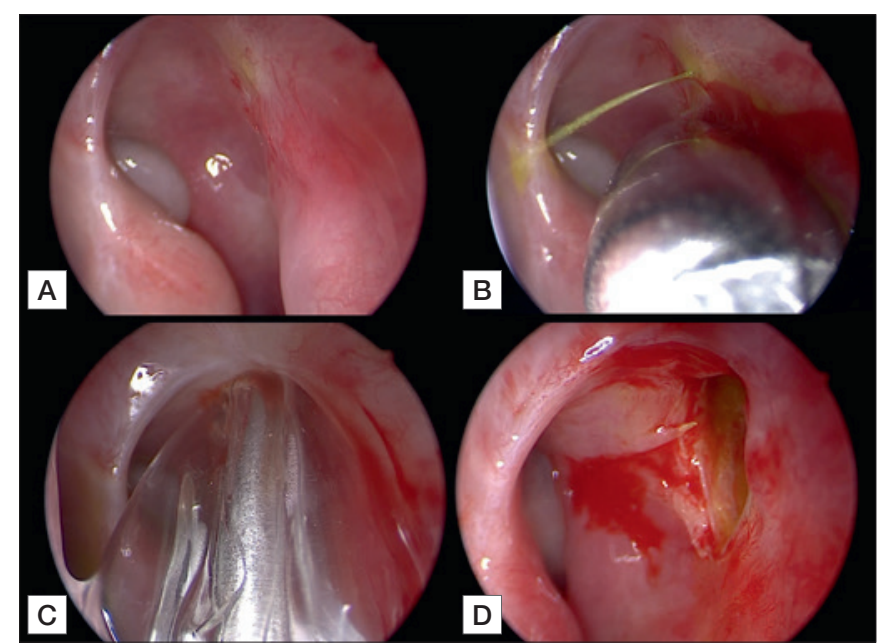

Figure 3. Using $30^{\circ}$ endoscope, the stenotic neo-rhinostomy is identified thanks to soft lavage of the lacrimal pathway with fluorescein, performed by an ophthalmologist (A); identification of the exact position of the neo-rhinostomy thanks to "high" pressure lavage of the lacrimal pathway with fluorescein (B); pneumatic dilatation of the neo-rhinostomy using a trans-nasal balloon catheter (C); enlarged revised neo-rhinostomy (D).

and lacrimal pathway irrigation remain the prevalent postsurgical management tools that can positively influence the surgical outcome of all forms of DALO. In fact, the periodic washing procedure of the lacrimal pathway and endoscopic treatment of the neo-rhinostomy can allow for better healing, and thus leading to better surgical outcomes ${ }^{15}$. As a result, post-surgical multidisciplinary approach remains of vital importance in long-term follow-up: in fact, on one hand the ophthalmologist can perform clinical evaluation of the lacrimal pathway, and on the other the ENT can en-

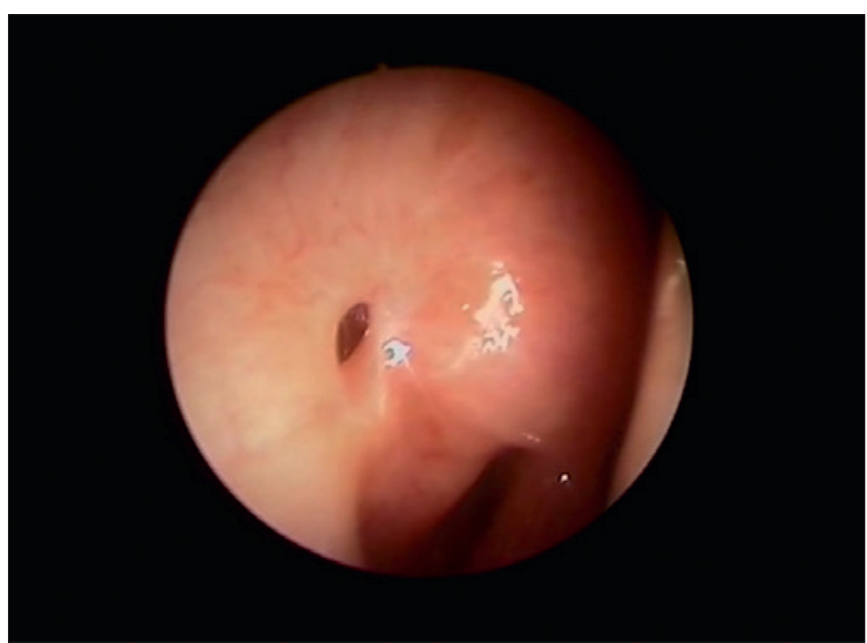

Figure 4. Endoscopic endonasal direct visualization of the neo-rhinostomy during a follow-up visit.

doscopically evaluate the neo-rhinostomy and provide additional information about the healing process (Fig. 4) ${ }^{15}$. At present, no definitive follow-up timing has been established, but it seems reasonable that this should be at least 6 months for non-oncologic DALO ${ }^{27}$, up to 18 months for failure surgeries ${ }^{32}$, and at least 5 years for oncologic DALO ${ }^{11}$.

\section{Conclusions}

The correct approach to lacrimal drainage system pathologies can be challenging due to the location of this apparatus and the different diseases that can influence physiological lacrimal flow. Considering both its diagnosis and treatment,

Table I. Recommendations for multidisciplinary assessment.

\begin{tabular}{lc}
\hline Diagnosis & Multidisciplinary assessment "strongly recommended" \\
\hline Diagnosis of lacrimal pathway disorders & Multidisciplinary assessment "optional" \\
\hline Treatment & Multidisciplinary assessment "optional" \\
\hline $\begin{array}{l}\text { Pump defects (e.g. medial ectropion or eyelid laxity) } \\
\text { Functional diseases (e.g. Dry eye or other causes) }\end{array}$ & $\begin{array}{c}\text { Multidisciplinary assessment "optional" } \\
\text { Proximal lacrimal obstructions }\end{array}$ \\
$\begin{array}{l}\text { Punctum diseases } \\
\text { Non-oncologic canaliculus diseases }\end{array}$ & Multidisciplinary assessment "recommended" \\
Primary/secondary oncologic canaliculus diseases & Multidisciplinary assessment "mandatory" \\
Distal lacrimal obstructions & \\
Distal congenital lacrimal obstruction & Multidisciplinary assessment "optional" \\
Non-oncologic distal acquired lacrimal obstruction & Multidisciplinary assessment "mandatory" \\
Oncologic distal acquired lacrimal obstruction & Multidisciplinary assessment "mandatory" \\
Post-surgical management and follow-up & \\
Post-surgical management and follow-up & Multidisciplinary assessment "mandatory" \\
\hline
\end{tabular}


a multidisciplinary approach with an ophtalmic plastic and ENT surgeons is frequently required, especially in distal forms, since such cooperation offers the best clinical approach available. In fact, even if most treatments of this apparatus are generally performed by an ophtalmologist, the additional information and surgical approach (END-DCR) that an ENT clinician provides can radically influence the decision making process and final success rate, making this cooperation of vital importance. Recommendations for multidisciplinary approach have been resumed in Table I.

\section{References}

1 Patel J, Levin A, Patel BC. Epiphora. Treasure Island (FL): StatPearls Publishing; 2020.

2 Nemet AY. The etiology of epiphora: a multifactorial issue. Semin Ophthalmol 2016;31:275-279. https://doi.org/10.3109/08820538.201 4.962163

3 Shen GL, Ng JD, Ma XP. Etiology, diagnosis, management and outcomes of epiphora referrals to an oculoplastic practice. Int J Ophthalmol 2016;9:1751-1755. https://doi.org/10.18240/ijo.2016.12.08

4 Berlucchi M, Tomenzoli D, Trimarchi M, et al. Dacryocystocele in the adult: etiology, diagnosis and treatment. Acta Otorhinolaryngol Ital 2001;21:100-104.

5 Giordano Resti A, Bertazzoni G, Trimarchi M. Nasolacrimal duct obstruction secondary to dental impaction. Eur J Ophthalmol 2014;24:611-613. https://doi.org/10.5301/ejo.5000410

6 Lanzillotta M, Campochiaro C, Trimarchi M, et al. Deconstructing IgG4-related disease involvement of midline structures: comparison to common mimickers. Mod Rheumatol 2017;27:638-645. https://doi. org/10.1080/14397595.2016.1227026

7 Trimarchi M, Bellini C, Fabiano B,. Multiple mucosal involvement in cicatricial pemphigoid. Acta Otorhinolaryngol Ital 2009;29:222-225.

8 Ullrich K, Malhotra R, Patel BC. Dacryocystorhinostomy. Treasure Island (FL): StatPearls Publishing; 2020.

9 Woog JJ. The incidence of symptomatic acquired lacrimal outflow obstruction among residents of Olmsted County, Minnesota, 19762000 (an American Ophthalmological Society thesis). Trans Am Ophthalmol Soc 2007;105:649-666.

10 Ali MJ. Iodine-131 Therapy and nasolacrimal duct obstructions: what we know and what we need to know. Ophthalmic Plast Reconstr Surg 2016;32:243-248. https://doi.org/10.1097/IOP.0000000000000647

11 Krishna Y, Coupland SE. Lacrimal sac tumors - a review. Asia Pac J Ophthalmol (Phila) 2017;6:173-178. https://doi.org/10.22608/APO.201713

12 Morassi ML, Trimarchi M, Nicolai P, et al. Cocaine, ANCA, and Wegener's granulomatosis. Pathologica 2001;93:581-583.

13 Ali MJ, Iram S, Ali MH, et al. Assessing the outcomes of powered endoscopic dacryocystorhinostomy in adults using the Lacrimal Symptom (Lac-Q) Questionnaire. Ophthalmic Plast Reconstr Surg 2017;33:65-68. https://doi.org/10.1097/IOP.0000000000000660

14 Juri Mandic J, Ivkic PK, Mandic K, et al. Quality of life and depression level in patients with watery eye. Psychiatr Danub 2018;30:471477. https://doi.org/10.24869/psyd.2018.471

15 Nair AG, Singh S, Kamal S, et al. The importance of endoscopy in lacrimal surgery. Expert Rev Ophthalmol 2018;13:257-265. https:// doi.org/10.1080/17469899.2018.1520635
16 Trimarchi M, Giordano Resti A, Vinciguerra A, et al. Dacryocystorhinostomy: evolution of endoscopic techniques after 498 cases. Eur J Ophthalmol 2020;30:998-1003. https://doi.org/10.1177/1120672119854582

17 Lefebvre DR, Freitag SK. Update on imaging of the lacrimal drainage system. Semin Ophthalmol 2012;27:175-186. https://doi.org/10.3109 /08820538.2012.711413

18 Nagi KS, Meyer DR. Utilization patterns for diagnostic imaging in the evaluation of epiphora due to lacrimal obstruction: a national survey. Ophthalmic Plast Reconstr Surg 2010;26:168-171. https://doi. org/10.1097/IOP.0b013e3181b8c747

19 Jones LT. Conjunctivodacryocystorhinostomy. Am J Ophthalmol 2018;187:xxxvi-xliv. https://doi.org/10.1016/j.ajo.2018.02.004

20 Eisenbach N, Karni O, Sela E, et al. Conjunctivodacryocystorhinostomy (CDCR) success rates and complications in endoscopic vs nonendoscopic approaches: a systematic review. Int Forum Allergy Rhinol 2021;11:174-194. https://doi.org/10.1002/alr.22668

21 Petris C, Liu D. Probing for congenital nasolacrimal duct obstruction. Cochrane Database Syst Rev 2017;7:CD011109. https://doi. org/10.1002/14651858.CD011109.pub2

22 Sathiamoorthi S, Frank RD, Mohney BG. Incidence and clinical characteristics of congenital nasolacrimal duct obstruction. Br J Ophthalmol 2019;103:527-529. https://doi.org/10.1136/bjophthalmol-2018-312074

23 Kapadia MK, Freitag SK, Woog JJ. Evaluation and management of congenital nasolacrimal duct obstruction. Otolaryngol Clin North Am 2006;39:959-977. https://doi.org/10.1016/j.otc.2006.08.004

24 Bansal O, Bothra N, Sharma A, et al. Congenital nasolacrimal duct obstruction update study (CUP study): paper I-role and outcomes of Crigler's lacrimal sac compression. Eye (Lond) 2020 Aug 10. https:// doi.org/10.1038/s41433-020-01125-1. Online ahead of print.

25 Lin AE, Chang YC, Lin MY, et al. Comparison of treatment for congenital nasolacrimal duct obstruction: a systematic review and meta-analysis. Can J Ophthalmol 2016;51:34-40. https://doi.org/10.1016/j.jcjo.2015.10.002

26 Bothra N, Vasanthapuram VH, Ali MJ. Infantile endoscopic dacryocystorhinostomy: indications, anatomical considerations, and outcomes. Ophthalmic Plast Reconstr Surg 2020;36:e100-103. https:// doi.org/10.1097/IOP.0000000000001615

27 Vinciguerra A, Nonis A, Giordano Resti A, et al. Best treatments available for distal acquired lacrimal obstruction: a systematic review and meta-analysis. Clin Otolaryngol 2020;45:545-557. https://doi. org/10.1111/coa.13551

28 Lin GC, Brook CD, Hatton MP, et al. Causes of dacryocystorhinostomy failure: External versus endoscopic approach. Am J Rhinol Allergy 2017;31:181-185. https://doi.org/10.2500/ajra.2017.31.4425

29 Indelicato P, Vinciguerra A, Giordano Resti A, et al. Endoscopic endonasal balloon-dacryoplasty in failed dacryocystorhinostomy. Eur J Ophthalmol 2020 Jul 14:1120672120942692. https://doi. org/10.1177/1120672120942692. Online ahead of print.

30 Indelicato P, Vinciguerra A, Giordano Resti A, et al. A case of endonasal balloon-assisted dacryoplasty after failure of endonasal dacryocystorhinostomy. Clin Case Rep 2020;8:1605-1609. https:// doi.org/10.1002/ccr3.2956

31 Vinciguerra A, Nonis A, Resti AG, et al. Impact of post-surgical therapies on endoscopic and external dacryocystorhinostomy: systematic review and meta-analysis. Am J Rhinol Allergy 2020;34:846-856. https://doi.org/10.1177/1945892420945218

32 Allon R, Cohen O, Bavnik Y, et al. Long-term outcomes for revision endoscopic dacryocystorhinostomy-the effect of the primary approach. Laryngoscope 2021;131:E682-E688. https://doi.org/10.1002/ lary. 28795 